\title{
Proteção intelectual através da indicação geográfica "Chã de Jardim" do artesanato em folha da bananeira (musa sp.) no Estado da Paraíba
}

Everaldo de França

Instituto Federal de Ciência, Tecnologia e Inovação do Espírito Santo (Ifes/Campus Barra de São Francisco)

Lucia Regina Rangel de Moraes Valente Fernandes

Coordenadora Geral de Indicações Geográficas e Registros do Instituto Nacional da Propriedade Industrial (INPI)

Recebido: 12/01/2015 Versão revisada (entregue): 17/07/2015 Aprovado: 11/08/2015

\begin{abstract}
Resumo
A construção de um Sistema de Indicação Geográfica Brasileiro tem sido pautada por uma variedade ampla de bens, envolvendo desde produtos industriais e agrícolas, serviços e até artesanato. Levando em consideração características sociais, culturais e geográficas, bem como a constituição étnica da população de Areia, no Estado da Paraíba, é de se supor o vasto conhecimento local que suas comunidades acumularam, e que procuram incorporar nas suas práticas cotidianas. Uma das práticas artesanais passíveis de proteção por Indicação Geográfica diz respeito ao uso do caule da bananeira (Musa sp.) como matéria prima para a fabricação de produtos manufaturados como bolsas, quadros, luminárias, pastas para eventos, utensílios para cozinha etc. O registro de IG para este tipo de atividade pode valorizar o conhecimento local sobre o uso sustentável da biodiversidade e promover as tradições culturais de Areia, trazendo melhorias para as comunidades envolvidas e, consequentemente, incrementando o desenvolvimento regional. O nome geográfico a ser protegido para o artesanato é "Chã de Jardim". Sugere-se que este nome seja protegido por Indicação de Procedência em vista da reputação dos produtos artesanais locais.
\end{abstract}

Palavras-chave | Artesanato; conhecimento local; Indicação Geográfica; Paraíba; propriedade intelectual.

Código JEL | O33; Q56; R11. 


\title{
INTELLECTUAL PROPERTY PROTECTION THROUGH THE GEOGRAPHICAL INDICATION “CHÃ DE JARDIM" OF THE BANANA LEAF HANDICRAFTS (MUSA SP.) IN THE STATE OF PARAIBA
}

\begin{abstract}
The construction of a Brazilian Geographical Indication System has been guided by a far wider range of goods, ranging from industrial and agricultural products, services, and even craftwork. Taking into account social, cultural and geographical characteristics, as well as the ethnic constitution of the population of Areia city in the State of Paraiba (Brazil), it is possible to suppose the vast local knowledge that this city's communities have accumulated over the decades while they seek to incorporate such knowledge in their daily practices. One of the artesanal activities subject to protection of Geographical Indication (IG) is the use of banana's plant (Musa sp.) stem as a raw material for some manufactured products such as handbags, light fixtures, folders for events, cooking utensils etc. The IG records for this type of activity can value the local knowledge regarding the sustainable use of biodiversity and promote the cultural traditions of Areia city, bringing also improvements to the communities involved and consequently increasing the regional development. The identified geographical name to be protected for craftwork is "Chã de Jardim". It is suggested that "Chã de Jardim" becomes protected by indication of origin whereas the artesanal products of this region feature good reputation.
\end{abstract}

Keywords | Craftwork; Geographical Indication; intellectual property; local knowledge; Paraíba.

JEL-Code | O33; Q56; R11.

\section{PROTECCIÓN DE LA PROPIEDAD INTELECTUAL A TRAVÉS DE LA INDICACIÓN GEOGRÁFICA “CHÃ DE JARDIM” DE LAS ARTESANÍAS DE HOJA DE PLÁTANO (MUSA SP.) EN EL ESTADO DE PARAÍBA}

\section{Resumen}

La construcción de un Sistema de Indicación Geográfica brasileño ha estado marcada por una amplia variedad de productos, que van desde productos industriales y agrícolas, servicios e incluso artesanía. Teniendo en cuenta las características sociales, culturales y geográficas, así como la constitución étnica de la población de Areia, en el estado de Paraíba (Brasil), es de suponer que el gran conocimiento local que acumularon sus comunidades, y que tratan de incorporar en sus prácticas cotidianas. Una de las prácticas artesanales que pueden acogerse a la protección de la indicación geográfica es la relacionada con el uso del tallo de plátano (Musa sp.) como materia prima para la producción de bienes manufacturados tales como bolsas, mesas, lámparas, carpetas para eventos, ropa de cocina, etc. El registro de IG para este tipo de actividad puede potenciar el conocimiento local sobre el uso sostenible de la biodiversidad y promover las tradiciones culturales de la arena, con lo que mejoran las comunidades involucradas y, en consecuencia, aumentar el desarrollo regional. El nombre geográfico que debe protegerse es el de "Chã de Jardim". Se sugiere que este nombre sea protegido por la indicación de la salida a la vista de la reputación de los productos de artesanía local.

Palabras-clave | Artesanía; conocimiento local; Indicación Geográfica; Paraíba; propiedad intelectual.

Código JEL | O33; Q56; R11. 


\section{Introdução}

Os territórios possuem propriedades naturais únicas, como tipos de solo, vegetação, relevo e clima, propriedades que, quando aliadas aos conhecimentos e ao saber fazer das comunidades locais ou tradicionais que residem nesses territórios, permitem que os produtos produzidos em certas regiões adquiram características peculiares próprias de produtos artesanais, as quais não são encontrados em qualquer outro lugar. As peculiaridades desses produtos lhes atribuem certo destaque, reputação, valor intrínseco e identidade própria, que os distinguem dos demais produtos de igual natureza disponíveis no mercado, tornando-os, a priori, mais valiosos. Constata-se uma procura cada vez maior por parte dos consumidores dos grandes centros urbanos por produtos de origem comprovada e, com isso, o surgimento de nichos de mercados, devido às mudanças de percepção e de comportamento dos consumidores modernos em relação aos produtos tradicionais ou industrializados (VALENTE et al., 2012).

A produção artesanal acompanha o homem desde os primórdios de sua história, passando por uma estruturação na Idade Média, quando a produção concentravase nas mãos dos artesãos que, posteriormente, se uniram para suprir necessidades do mercado de trabalho e consumo, configurando-se numa forma de trabalho de cooperação, comunitário (SANTOS et al., 2010). As políticas de valorização de produtos locais, tradicionais ou artesanais têm se constituído em ferramenta de desenvolvimento em áreas economicamente menos favorecidas (FREEMAN, 2010).

Quando um produto ou serviço é indicado pela referência a determinado local, as características de qualidade única decorrem dos atributos desse território (solo, clima, vegetação, topografia) e do conhecimento local (saber fazer adquirido tradicionalmente) dos produtores. E quando determinado bem conquistou notoriedade (por seus atributos), pode-se considerar que existe potencial para a proteção do ativo intangível Indicação Geográfica de acordo com o arcabouço legal brasileiro, em especial a Lei no 9.279 de 14 de maio de 1996.

No Brasil são possíveis duas espécies de IG: a Indicação de Procedência (IP) e a Denominação de Origem (DO), conforme Arts. 177 e 178 da Lei de Propriedade Industrial $n^{\circ} 9.279 / 96$. A IP refere-se ao nome geográfico de local que se tenha tornado conhecido como centro de extração, produção ou fabricação de determinado produto ou de prestação de determinado serviço. Envolve um componente humano/cultural, tais como saberes, práticas, modos e locais de transformação etc. (DA SILVA et al., 2010). Na Denominação de Origem (DO), as características de determinado produto ou serviço devem apresentar relação íntima com a região geográfica, ou seja, eles devem estar exclusiva ou essencialmente influenciados pelas particularidades naturais do ambiente 
geográfico, tais como solo, clima, vegetação etc. (BRASIL, 1996). Essas são as condições preliminares para que se possa obter um registro de IG (INPI, 2000).

As Indicações Geográficas (IG), em seu conceito mais amplo, referem-se a produtos com origem geográfica definida que incorporam ativos imateriais como reputação, fatores ambientais e humanos, proporcionando produtos com características próprias, que traduzem a identidade e a cultura de um determinado espaço geográfico. O registro de Indicação Geográfica (IG) permite dois tipos de proteção para territórios cujos produtos ou serviços são característicos do seu local de origem (INPI, 2000), o que lhes atribui reputação, valor intrínseco e identidade própria, além de os distinguir em relação aos seus similares disponíveis no mercado. São produtos que apresentam uma qualidade única em função de fatores naturais como solo, vegetação, clima - a proteção desse tipo de IG recebe o nome de Denominação de Origem (DO) e em função das peculiaridades do saber fazer da comunidade local recebe o nome de Indicação de Procedência (IP). A Indicação Geográfica é uma ferramenta coletiva de proteção e promoção de produtos tradicionais com reputação oriundos de determinadas regiões.

As IG surgiram para combater fraudes comerciais de produtos típicos de uma região (VALENTE et al., 2012). A ideia de mobilizar as Indicações Geográficas (IG) para proteger territórios que se destacam pelo uso do patrimônio genético e dos conhecimentos locais associados à biodiversidade, a fim de promover sua conservação, vem sendo proposta desde a década de 90 (CERDAN, 2009). Assim, nas pequenas comunidades ou em locais geograficamente peculiares e menos desenvolvidos, o reconhecimento de centro de produção de determinado produto ou serviço prestado como uma Indicação Geográfica (IG) pode ser alternativa viável de inserção no mercado face à impossibilidade dos pequenos produtores competirem com as grandes empresas, principalmente as do agronegócio (PORTO, 2007).

Determinados produtos ou serviços apresentam características regionais, distintas, as quais correspondem à expectativa do consumidor fiel à tipicidade e à sua unicidade. O comércio de produtos que se apresentavam como regionais, mas não apresentavam essas características, fez com que as IG surgissem para impedir que o nome do local fosse atrelado a itens de baixa qualidade.

Assim sendo, os produtos principalmente agrícolas classificados como tradicionais e originários de sistemas de produção locais vêm ganhando cada vez mais espaço no debate das políticas de desenvolvimento rural, inclusive no âmbito internacional, a exemplo da Europa (PROFETA et al., 2010). A garantia do reconhecimento da origem e da qualidade dos produtos regionais é uma das principais formas de assegurar sua reputação.

Quando um produto ou serviço possui em seu nome referência a determinado local e cujas características de qualidade única decorrem dos atributos desse território e do conhecimento local dos produtores, e quando esse artigo 
conquistou notoriedade (por seus atributos), pode-se considerar que esta tipicidade única apresenta originalidade criativa. Assim, trata-se de ativo intangível, imaterial, com potencial de proporcionar desenvolvimento econômico sustentável através de pesquisa, implantação de controle de práticas benéficas aos recursos naturais (FREENAN, 2010), como, por exemplo, nos casos da prática artesanal.

A estruturação de um sistema de IG tem sido pautada por uma variedade muito mais ampla de bens, envolvendo desde produtos industriais e agrícolas, além de serviços e até artesanato, como é o caso das legislações de alguns países, como Brasil, China e Índia (NIEDERLE, 2011). O artesanato, nesse contexto, é uma das mais ricas formas de expressão da cultura de uma comunidade, sendo, na maioria das vezes, a representação histórica de seus conhecimentos passados de geração em geração.

A proteção de alimentos com origem determinada é um processo sedimentado. Alguns destes produtos tiveram o reconhecimento como indicação geográfica na Comunidade Europeia. Mais recentemente, essa prática se firmou nos Estados Unidos, assim como no Brasil, cujo conceito está sendo desenvolvido lentamente no transcurso da história. De forma natural, produtores, comerciantes e consumidores comprovam que alguns produtos ou serviços de determinadas localidades apresentam qualidades particulares, atribuíveis a sua origem geográfica, e começam a identificá-los com a toponímia de origem. Este é o indício de um potencial de indicação geográfica.

No Brasil, as IG têm funcionado como uma ferramenta coletiva de promoção comercial de produtos e serviços de valor local e, em alguns casos, de aumento de autoestima e de instrumento de visibilidade. A pertinência da IG reside justamente no modo flexível com que permite aos indivíduos e organizações mobilizarem os recursos materiais e simbólicos peculiares de cada território, sendo interessante observar como a proteção de conhecimentos das comunidades locais e sociedades tradicionais vêm atingindo dimensões internacionais (ZANIRATO; RIBEIRO, 2007).

Pela ótica do desenvolvimento local, a IG possibilita a manutenção e revitalização de um produto ou de um serviço diferenciado, valorizando o conhecimento local sobre o uso sustentável da biodiversidade e promovendo as tradições culturais (NUNES et al., 2012). O reconhecimento de uma IG como centro de fabricação de determinado produto artesanal pode ser alternativa interessante de inovação para a inserção no mercado face à impossibilidade de pequenos produtores competirem com as grandes empresas do ramo do agronegócio (PORTO, 2007). Países em desenvolvimento, como o Brasil, têm demonstrado interesse especial na concessão de IG relacionadas a produtos não agroalimentares, como o artesanato e/ou manufaturas em tecido, couro e madeira, por exemplo, indo em outra direção ao que já vinha sendo concedido a produtos como arroz, café, chá e outras commodities. 
Segundo BELAS (2012), a indicação geográfica reúne elementos que favorecem a proteção cultural e valorização de uma produção coletiva para artesanatos historicamente regionalizados. O grande potencial do Brasil para registro de IG em produtos e serviços agropecuários motivou o Ministério da Agricultura a realizar um diagnóstico nacional (Figura 1).

\section{Figura 1 Regiões brasileiras potenciais para a solicitação de registro de Indicação Geográfica}

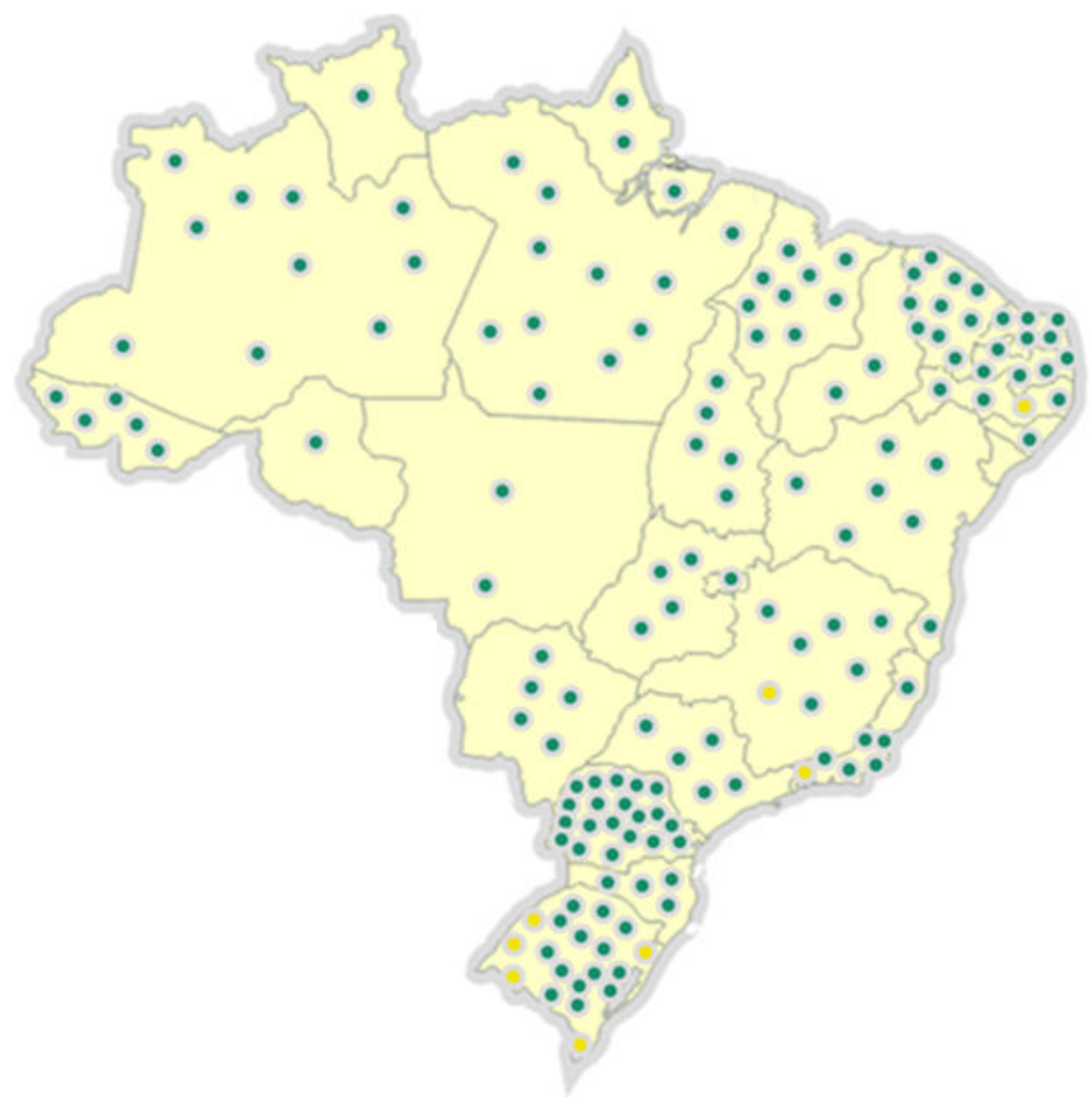

Fonte: Brasil (2015).

$\mathrm{Na}$ Paraíba, por exemplo, os produtos até então identificados no mapeamento com potencial de registro de indicação geográfica foram: cachaça, coco, abacaxi, arroz vermelho e citrus. No entanto, este mapa não indicou o potencial que existe no Estado para o artesanato, tal como o da Chã de Jardim.

O município de Areia, no Estado da Paraíba, foi primitivamente habitado por indígenas pertencentes à etnia Bruxaxá, um ramo da grande nação Cariri. A 
primeira noticia da exploração do território data do ano de 1625 (PARAÍBA, 2013), quando desbravadores portugueses percorreram a região, tendo um deles, de nome Pedro, se fixado no local à margem do cruzamento de estradas que eram caminho obrigatório dos boiadeiros e dos comboieiros dos sertões com destino à capital. Ali construiu um curral e uma hospedaria conhecida como "Pouso do Bruxaxá" e seu dono passou a ser denominado "Pedro Bruxaxá", dada a amizade que manteve com os índios Bruxaxás. A primeira sesmaria de que se tem noticia de requerimento no Sertão do Bruxaxá, em 1672, foi no local conhecido como Jardim. Posteriormente, o Sertão de Bruxaxá ficou conhecido como Terra dos Bruxaxás, uma referência aos índios que dominavam a região (ALMEIDA, 1980).

Em 1846, a Lei Provincial n ${ }^{\circ}$ 2, de 18 de maio de 1846, elevou o sertão de Bruxaxá a categoria de cidade (apesar de já existir oficialmente desde 1818), nomeando-a de Areia, uma referência a um rio que havia (e secou, sobrando apenas a areia) numa formação geográfica conhecida localmente por Chã, onde se instalou a primeira sesmaria no Jardim. Este local da cidade de Areia é até hoje conhecido como sítio Chã de Jardim. Outro sítio na cidade, chamado Chã da Pia (onde existe uma comunidade ceramista) parece também ter sido habitat de indígenas (AZEVEDO, 2005).

A população atual de Areia é de 23.837 habitantes, segundo dados do Instituto Brasileiro de Geografia e Estatística - IBGE, no ano de 2010. Além de indígenas Bruxaxás, os africanos também fizeram parte da formação populacional da cidade (SILVA E. F., 2010; SILVA, S. F., 2012). Antigo ponto de parada e abrigo para tropeiros que caminhavam em direção ao interior da Paraíba, assim como para boiadeiros e tropeiros que vinham do sertão com destino ao comércio do litoral paraibano no final do século XVII, Areia foi a primeira cidade da Paraíba a abolir a escravidão, na campanha promovida pelos abolicionistas Manoel da Silva e Rodolfo Pires. A cidade libertou o último escravo em 3 de maio de 1888 (SILVA, EF; 2010), embora os negros fizessem parte da estrutura econômica da região. Nessa época, a agricultura do município era basicamente voltada para a produção dos derivados da cana-de-açúcar. Atualmente, resquícios dos negros escravizados na cidade estão presentes nas 38 comunidades que reúnem quase 3.000 famílias identificadas nos sítios Novo Mundo e Senhor Bonfim, ambos distritos de Areia. Outros traços da população quilombola ainda são encontrados em cerca de 30 famílias no sítio Novo Mundo e 18 famílias do sítio Senhor do Bonfim (SALES et al., 2009; FEITOSA, 2011; MONTEIRO; GARCIA, 2012).

Em um mundo de relações econômicas globalizadas, as indicações geográficas necessitam de informações georreferenciadas para delimitação de área a ser protegida pelo nome geográfico, bem como de um conjunto de informações sobre o respectivo espaço geográfico para otimizar o potencial dos fatores naturais e humanos quanto às características da fabricação de artesanato, como o da comunidade Chã de Jardim. 
O conhecimento das populações ditas locais, tradicionais, autóctones ou indígenas, produzidos a partir de atividades e práticas coletivamente desenvolvidas, correspondem àquilo que a WIPO (World Intelectual Property Organization), define como "conhecimentos, inovações e práticas das comunidades locais e populações indígenas com estilos de vida tradicionais." (DUTFIELD, 2004). O uso de plantas medicinais pela comunidade quilombola de Areia pode constituir um acúmulo de conhecimento passado entre geração, tanto de quilombolas, como de indígenas que constituíram a população da cidade (SALES et al., 2009).

Durante o século XVIII, Areia assumiu expressão comercial estadual pelo cultivo de algodão e, posteriormente, investiu na plantação de café. É interessante destacar que já existiu na cidade, entre o século XIX e meados da década de 1960, cerca de 120 engenhos de cana de açúcar, dos quais vários ainda produzem cachaça artesanal e rapadura (FERREIRA, 2009), um cenário bem diferente do que foi observado década de 70. A extinção do programa de governo Proalcool na década de 1980 foi um dos fatores responsáveis pelo declínio dos grandes engenhos e das grandes usinas (SILVA; DINIZ, 2009), sendo que hoje se contabiliza apenas 28 deles em operação (AREIA, 2013). Talvez seja por esse motivo que atualmente em algumas comunidades o cultivo da banana abranja 35\% entre as quatro principais produções agrícolas (SANTANA et al., 2008; LIMA et al., 2009). Atualmente, a arquitetura colonial e a memória dos engenhos que restam se unem para promover o turismo e fortalecer a preservação do patrimônio histórico e cultural da região.

Areia é uma das poucas cidades localizadas no alto - situa-se precisamente à 618 metros de altitude em relação ao nível do mar - do Planalto da Borborema ou Chapada da Borborema, o mais marcante acidente do relevo do Estado da Paraíba (Figura 2). O município está localizado na mesorregião do Agreste e na microrregião do Brejo Paraibano (MOREIRA; MORAES, 2009). 
Figura 2 Localização da cidade de Areia no Estado da Paraíba, Brasil



Fonte: Moreira; Moraes (2009).

Areia limita-se geograficamente com os municípios de Alagoa Grande, Alagoa Nova, Alagoinha, Pilões, Remígio, Serraria e Arara e ocupa uma área de $269 \mathrm{~km}^{2}$ (IBGE, 2009). É abastecida pelos rios da bacia do Mamanguape (FIÚZA et al., 1998, p.17), possui clima ameno, bastante úmido no inverno, com temperaturas que chegam a variar entre $15^{\circ} \mathrm{C}$ à $8^{\circ} \mathrm{C}$ no inverno, bastante quente durante o dia no verão, mas ameno nas outras estações do ano (MOREIRA; MORAES, 2009).

O Nordeste destaca-se como a principal região produtora de banana do país, contribuindo com aproximadamente $41,2 \%$ da área cultivada. A Paraíba é o quarto produtor de banana da região Nordeste, sendo que a microrregião do Brejo contribui com aproximadamente $67,4 \%$ da produção estadual, tendo a cultura uma importância social e econômica muito grande regionalmente (BORGES; SOUZA, 2004; LIMA, 2010).

\section{Metodologia}

A pesquisa foi realizada em diversas visitas à Areia e, mais especificamente, ao povoado de Chã de Jardim. O histórico da notoriedade desse povoado foi realizado no acervo da Biblioteca Municipal Rodrigues de Aquino. Na segunda fase, a pesquisa consistiu da analise de fontes secundarias, tais como referências bibliográficas, leis, decretos, resoluções e pesquisas realizadas em outras fontes, tais como o Movimento Agroecológico da UFPB e a Associação Arte na Mão, 
ambas da cidade de Areia. Por ocasião das visitas, foram realizadas algumas entrevistas com a líder da comunidade e esclarecimentos posteriores foram feitos por e-mail. A pesquisa constituiu-se como estudo exploratório e analise documental que se referiam a um tipo de artesanato trabalhado por 20 mulheres chefes de família que vivem na zona rural da cidade de Areia. Foram coletadas no canal Youtube e no site da Prefeitura notícias com informações referentes ao artesanato desenvolvido na cidade de Areia/PB, quais comunidades envolvidas e quais seus costumes, assim como sua localização geográfica. As referências analisadas serviram como apoio para identificação do potencial de proteção.

\section{Resultado e discussão}

O artesanato de palha da bananeira (Musa sp.) na cidade de Areia - Uma das práticas artesanais passíveis de proteção por Indicação Geográfica (IG) das comunidades de Areia utiliza como matéria-prima dos produtos artesanais a parte mais robusta e espessa da bananeira, também conhecida pelas comunidades como a folha da bananeira (Musa sp.). No entanto, trata-se especificamente do pseudocaule da bananeira, utilizado em algumas técnicas artesanais (BORGES; SOUZA, 2004; GARAVELHO; MOLINA, 2005).

O Brasil é o segundo maior produtor mundial de banana (Musa sp.), sendo a região Nordeste a maior produtora (NOBREGA, 2006). Os produtos obtidos dessa matéria-prima vegetal pelas mulheres da comunidade Chã de Jardim são: bolsas, baús, quadros, luminárias, pastas para eventos, utensílios para cozinha, calçados etc. Fruto do conhecimento adquirido com as gerações anteriores, como o modo de utilizar matéria-prima vegetal da qual são feitas essas variedades artesanais, a comunidade comercializa seus itens em exposições e numa pequena loja localizada em um Centro de Ecoturismo no centro da cidade de Areia.

Assim, o nome geográfico sugerido a ser protegido é o nome da área geográfica da comunidade, ou seja, "Chã de Jardim", pelo qual o artesanato é conhecido. Sugere-se que o artesanato "Chã de Jardim" seja protegido por IP, já que os produtos artesanais da localidade apresentam reputação. No Brasil, verifica-se que, tanto para a IP quanto para a DO, a Lei 9.279/96 determina que, além da proteção do nome, a proteção se estenda à representação gráfica ou figurativa que esta utilizar, bem como à representação geográfica do local que leve o nome da IG.

No que diz respeito ao processo produtivo em si, é possível a elaboração pelas artesãs locais de um Regulamento de Uso simplificado desde a matéria-prima vegetal da qual são feitos os produtos, assim como regras no que se refere à metodologia de confecção dos produtos artesanais, que deve observar alguns procedimentos, tais como: 
- a bananeira tem que ter dado fruto;

- o corte do caule deve observar aproximadamente $20 \mathrm{~cm}$ do chão;

- a primeira palha (primeira folha da camada do caule) deve ser descartada;

- deve ser obtido inicialmente apenas 6 tipos de fios das folhas selecionadas;

- escolha do fio nobre ( $1^{\circ}$ fio) das extremidades longitudinais;

- os outros 5 fios sequenciais e demais folhas/palhas são colocados em solução de hipoclorito por cerca de 3 horas;

- todas as fibras e fios devem sofrer um processo de desidratação, preferencialmente ao ar livre;

- a confecção dos produtos é totalmente manual e envolve colagem e costura das fibras.

No regulamento de uso é possível identificar as vantagens da certificação de produtos regionais, evidenciando a preservação e manutenção de áreas rurais específicas (YOKOBATAKE et al., 2013). Com o procedimento acima descrito é possível manufaturar ou fazer acabamentos em uma diversidade de produtos, tais como os apresentados a seguir:

\section{Figura 3 Produtos confeccionados}
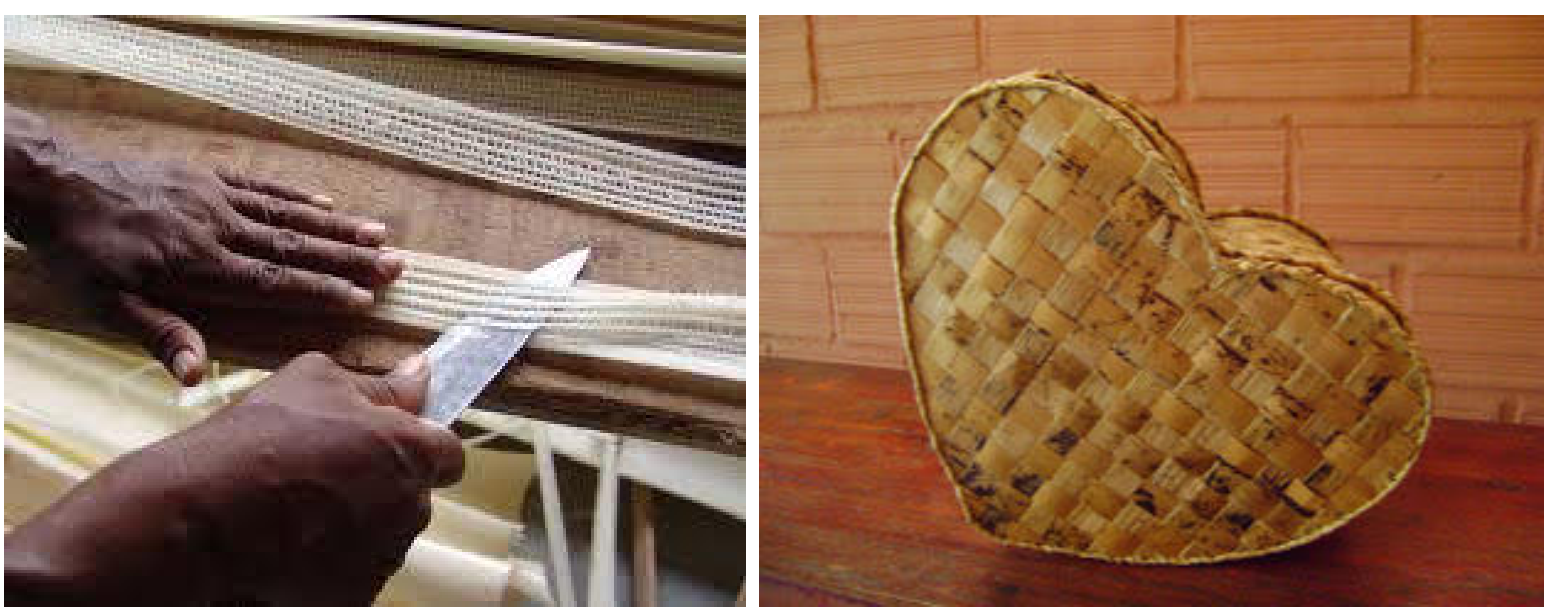

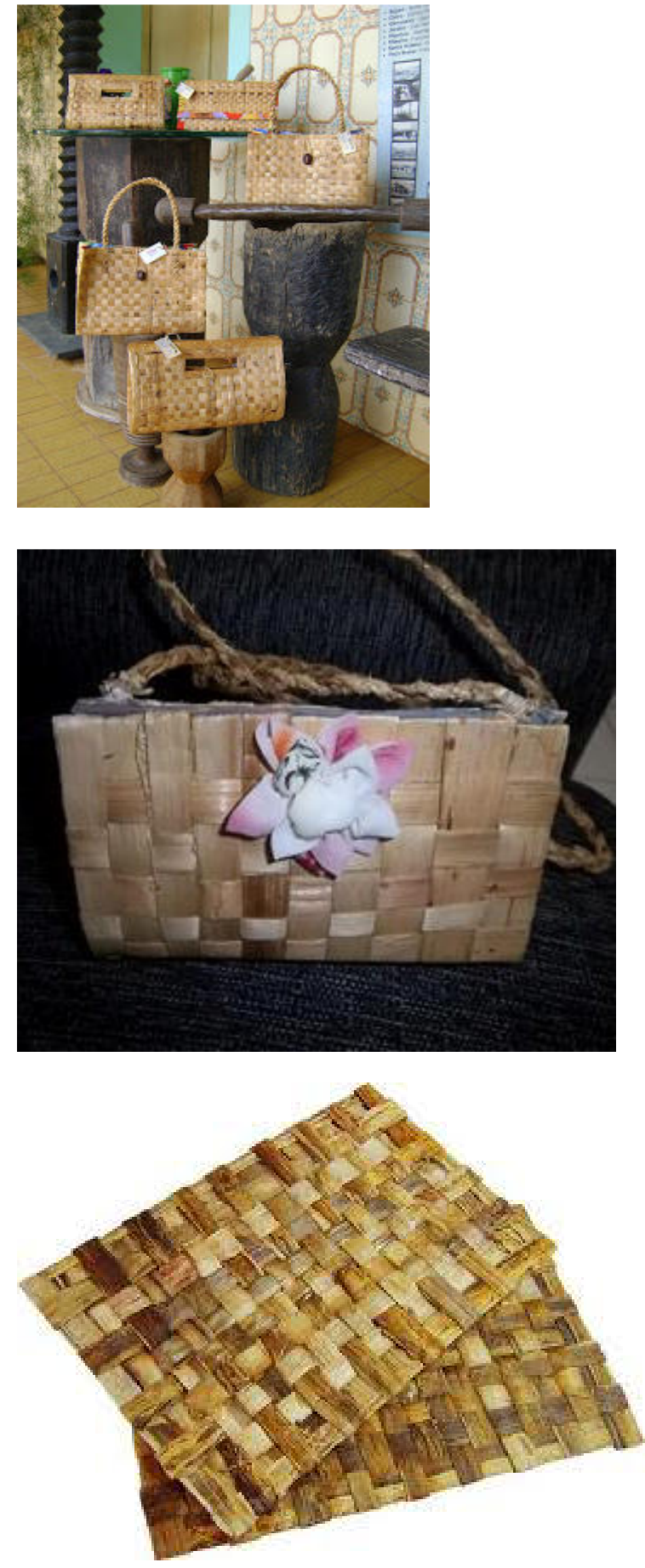
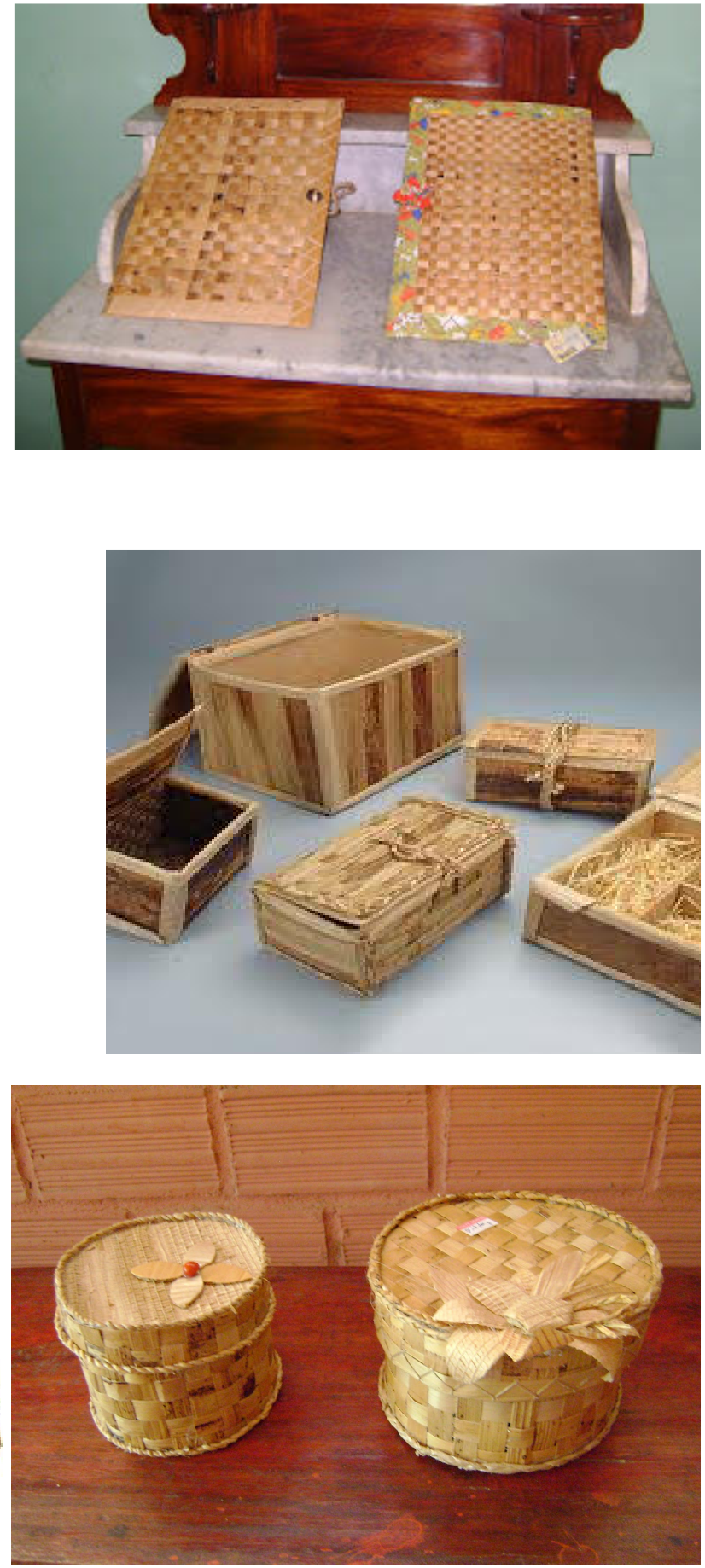

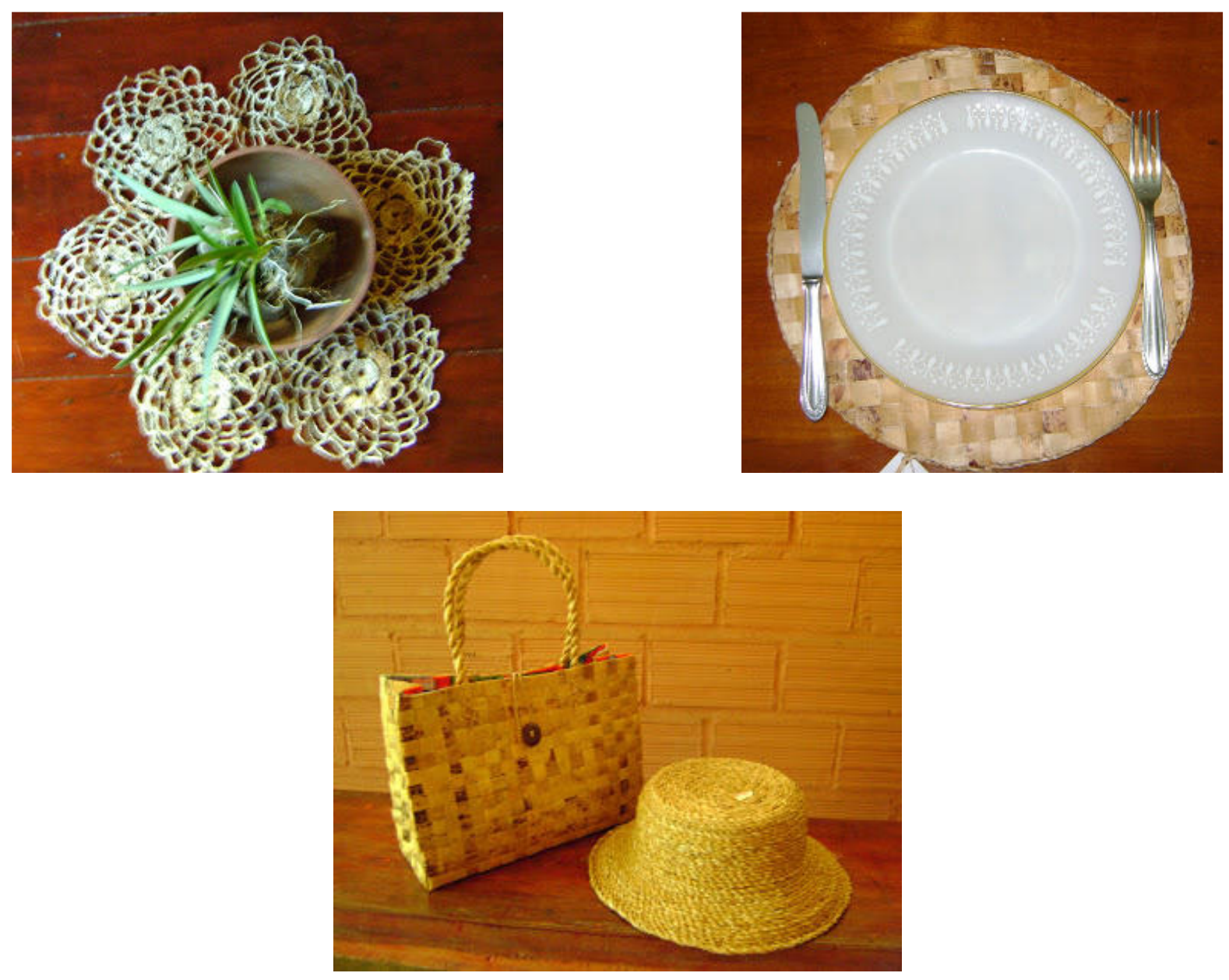

Fonte: Silva, M. A. (2012). Fotos autorizadas por Luciana de Souza Balbino.

Dentre os benefícios advindos do registro de indicação geográfica destacam-se os socioculturais, tais como a inserção de produtores locais nos arranjos produtivos de regiões desfavorecidas, e os benefícios ambientais (preservação da biodiversidade e dos recursos genéticos locais e a preservação do meio ambiente), segundo Yokobatake et al. (2013) e Vieira; Pellin (2015). Assim sendo, o reconhecimento da indicação geográfica Chã de Jardim deverá agregar valor ao artesanato local, sendo possível associá-lo ao turismo e, consequentemente, contribuir para a melhoria do orçamento familiar da comunidade e facilitar sua inclusão social.

A comunidade de senhoras de Chã de Jardim pretende criar uma rede socioeconômica solidária com uma proposta de controle para o uso da representação gráfica vinculada à IG. Entretanto, no que tange ao número de pessoas envolvidas, já existe um grupo de 20 famílias, representado por 20 mulheres, chamado de "Arte na Mão" (SOUZA, 2011). Essas mulheres residem e reúnem-se em Chã de Jardim, distante 9 quilômetros da cidade de Areia. Com o auxílio da líder comunitária local, Luciana de Souza Balbino, essas mulheres organizam-se atualmente na Associação para o Desenvolvimento Sustentável da 
Chã de Jardim (ADESCO), fundada em 22 de setembro de 2005, com o apoio da Empresa de Assistência Técnica e Extensão Rural (EMATER), do Projeto COOPERAR do Governo do Estado da Paraíba, do SEBRAE e do Serviço Nacional de Aprendizagem Rural da Paraíba (SENAR), que desempenharam um papel indispensável na consolidação do projeto de artesanato "Arte na Mão".

Chã de Jardim é um território de Mata Atlântica que compreende uma área de 607 hectares, onde fica o Parque Estadual Mata do Pau Ferro, bastante visitado por turistas por conta das várias cachoeiras e trilhas. Os produtos artesanais da Associação são vendidos no local, no Centro do Ecoturismo, um espaço da Associação Espaço do Artesão de Areia.

Além disso, a comunidade Chã de Jardim da cidade de Areia recebe o apoio da prefeitura pela disponibilização do espaço físico para a exposição e venda dos produtos no Centro de Artesanato Dom Adalto, localizado no centro da cidade. O Centro de Ciências Agrárias da Universidade Federal da Paraíba, Campus II, localizado em Areia é um órgão que tem concedido apoio às comunidades locais da cidade. A universidade, principalmente através do Movimento Agroecológico (MAE), tem desenvolvido trabalhos científicos com o apoio da comunidade (FRANCISCO; TORRES, 2011).

Embora a tradicional cultura canavieira, ainda dominante no seu espaço agrário, em outras comunidades da cidade de Areia o cultivo da banana é predominante e, nelas, $40 \%$ das famílias participa de alguma associação ou sindicato (SANTANA et al., 2008; SILVA; DINIZ, 2009; LIMA et al., 2009), o que pode facilitar os procedimentos para o registro de Indicação Geográfica estabelecidos pelo INPI (INPI, 2000).

\section{Conclusões}

É promissora e necessária alguma forma de proteção do artesanato e do conhecimento local, tão importante na sustentabilidade da identidade cultural em Chã de Jardim. O nome geográfico identificado e com potencial de proteção através da IG a ser protegido para o artesanato é "Chã de Jardim". Para que o artesanato da cidade de Areia de fato venha a se concretizar como uma IG é preciso estruturar e desenvolver uma série de atividades que incluem a disseminação do tema propriedade industrial para a comunidade envolvida, tanto para sensibilização das artesãs como dos gestores públicos municipais. Isso facilitaria a elaboração de um estatuto pela Associação que executa ações de proteção e de sustentabilidade da IG, do resgate histórico da técnica de trabalho com a palha da bananeira, da comprovação da reputação deste artesanato, da criação de uma representação gráfica da IG, da criação de regulamento de uso e estrutura de controle da IG com informações e normas sobre o processo de 
produção das peças artesanais e na comercialização. Além do artesanato feito da matéria-prima vegetal do caule da bananeira, as informações levantadas neste estudo sugerem que outras comunidades da cidade de Areia detém outros saberes com potencial de proteção por Indicação Geográfica, como o trabalho manual com cerâmica e a fabricação artesanal de cachaça e rapadura.

A IG é também uma oportunidade para o desenvolvimento de outras atividades na região, como turismo e gastronomia, que são promovidos graças à reputação dessa indicação geográfica. Por fim, as características geográficas da Chã de Jardim podem instigar a reflexão de proteção de variedades de sementes, cultivares e até mesmo de plantas, através de indicação geográfica do tipo Denominação de Origem (DO).

Agradecimentos: à Luciana Balbino de Souza, líder da comunidade, que autorizou a divulgação das fotos do artesanato "Arte na Mão" fabricado pelas mulheres de Chã de Jardim.

\section{Referências}

ALMEIDA, H. Brejo de Areia: Memórias de um Município. 2. ed. João Pessoa: Editora Universitária/UFPB, 1980.

AREIA. Prefeitura Municipal de Areia. Pontos Turísticos. Disponível em: http://areia.pb.gov.br/turismo/pontos-turisticos.php. Acesso em: 10 jan. 2013.

AZEVEDO, C. A. Moradores de comunidade rural fabricam utensílios de barro que são vendidos no Brejo Paraibano. Jornal A União, 2005. Disponível em: http://pt.scribd.com/doc/46244978/CERAMISTAS-DE-CHA-DA-PIA-porCarlos-A-Azevedo-Jornal-A-Uniao-02nov05-Joao-Pessoa-Paraiba. Acesso em: 21 nov. 2013.

BELAS, Carla Arouca. Indicações Geográficas e salvaguarda do patrimônio cultural: artesanato de capim dourado Jalapão-Brasil. 2012. 266 p. Tese (Doutorado em Desenvolvimento, Agricultura e Sociedade). Instituto de Ciências Humanas e Sociais, Universidade Federal Rural do Rio de Janeiro, Rio de Janeiro, RJ, 2012. Disponível em: http://r1.ufrrj.br/cpda/wp-content/uploads/ 2012/07/Tese-Carla-Arouca-Belas.pdf. Acesso em: 2 mai. 2014.

BORGES, A. L.; SOUZA, L. S. O cultivo da bananeira. Embrapa Mandioca e Fruticultura. 279 p. 2004. Disponível em http://www.cnpmf.embrapa.br/ publicacoes/Livro_Banana.pdf. Acesso em: 25 jul. 2013. 
BRASIL. Lei n. 9.279, de 14 de maio de 1996. Lei da Propriedade Industrial. Brasília: Ministério do Desenvolvimento, Indústria e Comércio Exterior, 1996.

Ministério da Agricultura, Pecuária e Abastecimento. Produtos Potenciais. Disponível em: http://www.agricultura.gov.br/desenvolvimentosustentavel/indicacao-geografica/produtos-potenciais. Acesso em: 15 jul. 2013.

CERDAN, C. Valorização dos produtos de origem e do patrimônio dos territórios rurais no sul do Brasil: contribuição para o desenvolvimento territorial sustentável. Revista Politica e Sociedade, n. 14, p. 277-299, 2009. Disponível em: http://www.periodicos.ufsc.br/index.php/politica/article/viewFile/11626/10961 Acesso em: 13 jun. 2013.

DA SILVA, A. L. et al. Delimitação geográfica da área: homem, história e natureza. In: CERDAN, C. M. et al. (Org.). Curso de propriedade intelectual \& inovação no agronegócio: Módulo II, indicação geográfica. 2. ed. Brasília: MAPA, Florianópolis: SEaD/ UFSC/ FAPEU, 2010. Cap. 4, p. 129-158.

DUTFIELD, Graham. Repartindo benefícios da biodiversidade - qual o papel do sistema de patentes? In: VARELLA, Marcelo D.; PLATIAU, Ana Flávia B. (Org.). Diversidade biológica e conhecimentos tradicionais. Coleção Direito Ambiental, v. 2, p. 57-107, 2004.

DZUSIAN, J. I.; NUNES, I. L. Indicações geográficas brasileiras e impacto sobre bens agrícolas e/ou agroindustriais. Revista GEINTEC, São Cristóvão/SE, v. 2, n. 4, p. 413-426, 2012.

FEITOSA, S. T. Comunidade quilombola engenho do Bom Fim e suas manifestações de cultura e lazer. 24 p. Trabalho de Conclusão de Curso. Faculdade de Educação Física. Universidade Estadual da Paraíba. Campina Grande. 2011. Disponível em: http://dspace.bc.uepb.edu.br:8080/xmlui/ bitstream/handle/123456789/248/PDF\%20-\%20Samara \%20Trajano $\% 20$ Feito sa.pdf?sequence=1. Acesso em: 2 jul. 2013.

FERREIRA, A. C. F. A situação dos engenhos de cachaça e rapadura do município de Areia/PB. Anais do XXV Simpósio Nacional de História, Fortaleza. 2009. Anais... Disponível em: http://anpuh.org/anais/wp-content/uploads/mp/ pdf/ANPUH.S25.0909.pdf. Acesso em: 18 jun. 2013.

FRANCISCO, P. M. S; TORRES, E. J. M. Movimento Agroecológico - MAE: 18 anos difundido a agroecologia. Cadernos de Agroecologia, n. 16, n. 2, p. 1-5, 2011. 
GARAVELHO, M. E. P. E; MOLINA, S. M. G. O artesanato com fibra de bananeira. In: XIII Reunião itinerante de fitossanidade do Instituto Biológico Cultura da Banana. Anais... p. 86-92, 2005. Disponível em: http://www.biologico.sp.gov.br/rifib/XIII\%20RIFIB/garavello.pdf. Acesso em 2 jul. 2013.

INPI. Instituto Nacional da Propriedade Industrial. Resolução n. 75 de 28 de novembro de 2000. Estabelece as condições para o registro das indicações geográficas. Rio de Janeiro: INPI, 2000. 7 p. Disponível em: http://www.inpi.gov.br/portal/artigo/resolucao n 75 2000. Acesso em: 12 jun. 2013.

LIMA, E. Q. Diagnóstico da produção de bananas cultivadas em sistema convencional e orgânico no município de Bananeiras. 2010. Disponível em: http://www.ebah.com.br/content/ABAAAfPKwAB/diagnostico-producao-ban anas-cultivadas-sistema-convencional-organico-no-municipio-bananeiras. Acesso em: 22 jun. 2013.

LIMA, M. B.; BATISTA, J. L.; BRITO, C. H.; LOPES, E. B. Diagnóstico da produção agroecológica do município de Areia/PB. Engenharia Ambiental, v. 6, n. 2, p. 251-263, mai./ago., 2009.

MONTEIRO, K. S.; GARCIA, M. F. Propriedade da terra, trabalho e território: o processo de destruição e reinvenção dos territórios do Povo Negro na Comunidade de Gurugi, Paraíba. Revista OKARA: Geografia em debate, v. 6, n. 1, p. 69-98, 2012.

MOREIRA, F. D.; MORAES, C. G. M. S. M. O desenvolvimento urbano de Areia/PB: contribuição aos estudos de morfologia e história urbana no Brasil. Risco - Revista de Pesquisa em Arquitetura e Urbanismo do Programa de PósGraduação do Departamento de Arquitetura e Urbanismo da USP, v. 9, n. 1, p.133-153, 2009.

NIEDERLE, P. A. Compromissos para a qualidade: projetos de indicação geográfica para vinhos no Brasil e na França. 2011. 263 p. Tese (Doutorado em Desenvolvimento, Agricultura e Sociedade). Instituto de Ciências Humanas e Sociais, Universidade Federal Rural do Rio de Janeiro, Rio de Janeiro, 2011. Disponível em: http://www.supremapatentes.com.br/servicos/151-ip-do.html. Acesso em: 13 abr. 2013. 
NÓBREGA, J. P. R. Produção de mudas de bananeira (Musa sp. AAB) em função da poda e doses de nitrogênio e boro. 97 f. Dissertação (Mestrado em Agronomia) Centro de Ciências Agrárias, Universidade Federal da Paraíba, Areia/ Paraíba, 2006. Disponível em: http://www.cca.ufpb.br/ppga/pdf/mestrado/Josepires-ms06.pdf. Acesso em: 1 abr. 2013.

NUNES, G. S.; BANDEIRA, M. G. A.; NASCIMENTO, J. S. Indicações geográficas (IG): instrumento de desenvolvimento sustentável. Revista GEINTEC, São Cristóvão/SE, v. 2, n. 4, p. 344-352, 2012.

OCDE - Organização para Cooperação Econômica e Desenvolvimento. Manual de Oslo: proposta de diretrizes para coleta e interpretação de dados sobre inovação tecnológica. Rio de Janeiro: FINEP. 2005. Disponível em http://www.finep.gov.br/imprensa/sala imprensa/manual de oslo.pdf. Acesso em: 13 abr. 2013.

PARAÍBA. Governo do Estado da Paraíba. Disponível em http://www.fcja.pb.gov.br/cidade natal.shtml. Acesso em: 10 jan. 2013.

PORTO, P. C. R. Indicações geográficas: a proteção adequada deste instituto jurídico visando o interesse público nacional. 134 p. Monografia (Especialização) Programa de Pós-Graduação da Faculdade de Direito da Universidade do Estado do Rio de Janeiro. 2007.

PROFETA, A.; BALLING, R.; SCHOENE, V.; WIRSIG, A. Protected Geographical Indications and Designations of Origin: An Overview of the Status Quo and the Development of the Use of Regulation (EC) 510/06 in Europe, With Special Consideration of the German Situation. Journal of International Food \& Agribusiness Marketing, v. 22, n. 1-2, p.179-191, 2010.

SANTANA, E. P. V. R. S; OLIVEIRA, A. R.; OLIVEIRA, F. J. M. Diagnóstico sócio econômico da comunidade de Pindoba, município de Areia/PB. Revista Verde, v. 3, n. 4, p. 46-62, out./dez., 2008.

SALES, G. P. S.; ALBUQUERQUE, H. N.; CAVALCANTI, M. L. F. Estudo do uso de plantas medicinais pela comunidade quilombola Senhor do Bonfim Areia-PB. Revista de Biologia e Ciências da Terra, Suplemento Especial, n.1, 2. semestre, p. 31-36, 2009. Disponível em: http://eduep.uepb.edu.br/rbct/ sumarios/pdf/6bomfim.pdf. Acesso em: 2 jul. 2013. 
SANTOS, T. S. NASCIMENTO, J. P. B.; BORGES, G. F.; MORAES, A. F. O.; TEIXEIRA, E. O Artesanato como elemento impulsionador no desenvolvimento local. In: VII Simpósio de Excelência em Gestão e Tecnologia. 2010. Anais... Disponível em: http://www.aedb.br/seget/artigos $10 / 523$ O\%20Artesanato $\% 20$ como $\% 20$ elemento $\% 20$ impulsionador $\% 20$ no $\% 20$ Desenvolvimento $\% 20$ Local.pdf. Acesso em: 13 abr. 2013.

SILVA, E. F. Escravidão e resistência escrava na cidade d'Arêa oitocentista. 188 p. Dissertação (Mestrado em História) Centro de Humanidades, Programa de Pós-Graduação em História, Universidade Federal de Campina Grande, Campina Grande/PB, 2010. Disponível em: http://www.yumpu.com/pt/document/ view/12606709/mestrado-eleonora-felix-ufcg. Acesso em: 18 jun. 2013.

SILVA, J. B.; DINIZ, L. S. O binômio engenho-pobreza no brejo paraibano: uma análise sócio-espacial da relação campo-cidade na produção das periferias rururbanas do município de Areia/PB. In: XIX Encontro Nacional de Geografia Agrária, São Paulo. 2009. Anais... Disponível em: http://www.geografia.fflch. usp.br/inferior/laboratorios/agraria/Anais\%20XIXENGA/artigos/Silva JB.pdf. Acesso em: 2 jul. 2013.

SILVA, M. A. Chã de Jardim em movimento. 2012. Blog do Marcelo Alexandre. Disponível em: http://marcello-alexandre.blogspot.com.br/2012/07/ arte-na-mao-artesanato-na-palha-da.html. Acesso em: 20 set. 2013.

SILVA, S. F. As fontes e as práticas religiosas da irmandade do rosário dos pretos em Areia - PB. Paralellus, Recife, ano 3, n. 5, jan./jun., p. 109-120, 2012.

SOUZA, L. B. Em busca de um sonho: a experiência do programa saberes da terra na comunidade Chã de Jardim em Areia. In: I Encontro de Pesquisas e Práticas em Educação do Campo da Paraíba. Centro de Educação, UFPB, 2011. Anais... Disponível em: http://www.ieppecpb2011.xpg.com.br/conteudo/GTs/ GT\%20-\%2004/15.pdf. Acesso em: 23 jan. 2014.

TONIET'TO, J. et al. Zoneamento vitivinícola e o desenvolvimento de indicações geográficas de vinhos. In: XXII Congresso Brasileiro de Fruticultura, 22-26 de outubro de 2012, Bento Gonçalves/ RS. Anais... Disponível em http://www.congressofruticultura2012.com.br/anais/conferencistas/textos-pale stras/Jorge Tonietto.pdf. Acesso em: 3 mar. 2013.

VALENTE, M. E. R. et al. Indicação geográfica de alimentos e bebidas no Brasil e na União Europeia. Ciência Rural, Santa Maria, v. 42, n. 3, p. 551-558, 2012. 
VIEIRA, A. C. P.; PELLIN, V. As Indicações Geográficas como estratégia para fortalecer o território - o caso da Indicação de Procedência dos Vales da Uva Goethe. Desenvolvimento em Questão, ano 13, n. 30, abr./jun., p. 155-174, 2015.

YOKOBATAKE, K. L. A.; LOPES, K. S. M.; PINHEIRO, R. S. B. Denominação de origem e indicação geográfica de produtos agrícolas. Fórum Ambiental da Alta Paulista, v. 9, n. 7, p. 70-79, 2013.

ZANIRATO, S. H.; RIBEIRO, W. C. Conhecimento tradicional e propriedade Intelectual nas organizações multilaterais. Ambiente \& Sociedade, Campinas, $\mathrm{n}$. 1, p. 39-55, 2007.

Endereço para correspondência:

Everaldo de França - everaldo.franc@gmail.com

Av. Arino Gomes Leal, 1700, Bairro Santa Margarida, Campus Colatina 29.700-558 Colatina/ES, Brasil

Lucia Regina Rangel de Moraes Valente Fernandes - luciareg@inpi.gov.br Rua S. Bento, $1,18^{\circ}$ andar

20.090-010 Rio de Janeiro/RJ, Brasil 